\title{
Tropomyosin Alpha-3 Chain Isoform 2
}

National Cancer Institute

\section{Source}

National Cancer Institute. Tropomyosin Alpha-3 Chain Isoform 2. NCI Thesaurus. Code C129382.

Tropomyosin alpha-3 chain isoform 2 (248 aa, $30 \mathrm{kDa}$ ) is encoded by the hT M5 allele of the human TPM3 gene. This protein plays a role in the stabilization of the actin cytoskeleton. 